\title{
Membangun Spiritualitas Kristen Warga Binaan di Lapas Umum Kelas II A Tanjungpinang
}

\author{
Fredy Simanjuntak*1, Candra Gunawan Marisi ${ }^{2}$, Ardianto Lahagu ${ }^{3}$, Benteng M. M. Purba ${ }^{4}$, \\ Agustinus Sihombing 5 \\ 1, 2, 5 Prodi Teologi, STT REAL Batam \\ ${ }^{3,4}$ Prodi PAK, STT REAL Batam \\ *fredygrace@gmail.com
}

\begin{abstract}
Spirituality is the value or understanding possessed by humans in behaving with one another, even their relationship with God which is influenced by the environment, experience and knowledge. Every human being has Spirituality in him, and spirituality affects both individual behavior in society or other individuals. The Indonesian state by law certainly has the goal of creating good community conditions in the midst of society. The state wants the assisted citizens or Correctional Institution communities to receive guidance in order to create this good condition. However, this wish has not been carried out properly, due to a lack of experts. So how does Christianity view this? Certainlly the question will arise as well what should be done to bring the assisted people from living the wrong way to the right direction by cultivating their spirituality and of course teaching them Christian spirituality.

Keywords: Building; Spirituality; Christian; Correctional Institution
\end{abstract}

\begin{abstract}
Abstrak
Spritualitas adalah nilai atau pemahaman yang dimiliki oleh mansuia dalam berperilaku satu dengan yang lainya bahkan hubungan dengan Tuhan yang dipengaruhi oleh lingkungan hidup, pengalaman dan pengetahuan. Setiap manusia memiliki Spiritualitas dalam dirinya, dan spritiualitas mempengaruhi baik buruknya perilaku individu ditengah-tengah masyarakat atau terhadap individu lainnya. Negara Indonesia secara hukum tentunya memiliki tujuan agar terciptanya kondisi masyarakat yang baik ditengah-tengah masyarakat. Negara ingin warga binaan atau masyarakat lapas mendapat binaan agar terciptanya keadaan yang baik tersebut. Namun keinginan itu belum terlaksana dengan baik, dikarenakan kurangnya tenaga ahli. Lantas bagaimana kekristenan memandang hal ini. Tentunya akan timbul pertanyaan juga apa yang harus dilakukan untuk membawa warga binaan dari hidup yang salah menuju arah yang benar. Tentu saja dengan membina spiritualitas mereka dan tentunya mengajarkan kepada mereka spiritualitas Kristen.

Kata kunci: Membangun; Spritualitas; Krsiten, Lembaga; Permasyarakatan
\end{abstract}

\section{PENDAHULUAN}

Berdasarkan maksud dan tujuan undang-undang nomor 12 tahun 1995 tentang Permasyarakatan, sangat jelas memaparkan bahwa keinginan Negara menciptakan kondisi yang lebih baik dalam membina warga binaan, sehingga kelak warga binaan ini dapat berguna ditengah-tengah masyarakat. Akan tetapi Pelaksanaan pembinaan di Lembaga Pemasyarakatan ini, belum dapat dilakukan secara maksimal. Hal ini disebabkan kurangnya tenaga ahli yang kompeten dibidangnya khususnya kerohanian yang ditunjang dengan kemampuan dalam melakukan pembinaan dengan pendekatan kekeluargaan yang dapat menyentuh perasaan warga binaan. Guna mencapai tujuan tersebut, pemerintah bekerja sama dengan masyarakat memberikan pembinaan yang bersifat material, spiritual, dan keterampilan kepada para Narapidana. ${ }^{1}$

Oleh karena itu penulis melihat betapa pentingnya memberikan pembinaan kerohanian kepada Warga Binaan yang ada di Lapas Umum Kelas II A Tanjungpinang, dalam memberikan pemahama materi tentang Spiritualitas Kristen yang kiranya dapat mengubah karakter dan sikap warga binaan. Dengan pelayanan ini diharapkan warga binaan menjadi mengerti apa itu spiritualitas Kristen dan dapat mengevaluasi sikap, pemikiran dan perasaan mereka sehingga memiliki Spiritualitas Kristen

${ }^{1}$ SK Menteri Kehakiman No. M.02. PK. 04.10 Tahun 1990 Tentang Pembinaan Narapidana/Tahanan, Bab VII Huruf C. 
yang baik dan benar.

\section{METODE}

Jurnal ini disusun dengan menggunakan metode Kualitatif Studi Kasus, dengan mengkaji secara mendalam dan mempelajari latar belakang dari fenomena-fenomena yang terjadi dalam kegitan pengabdian masyarakat, pengaruh masyarakat dengan narapidana dan juga perilaku perilaku narapidana terhadap hukum. Kegiatan PkM ini dilaksanakan awal Januari sampai dengan April 2018.

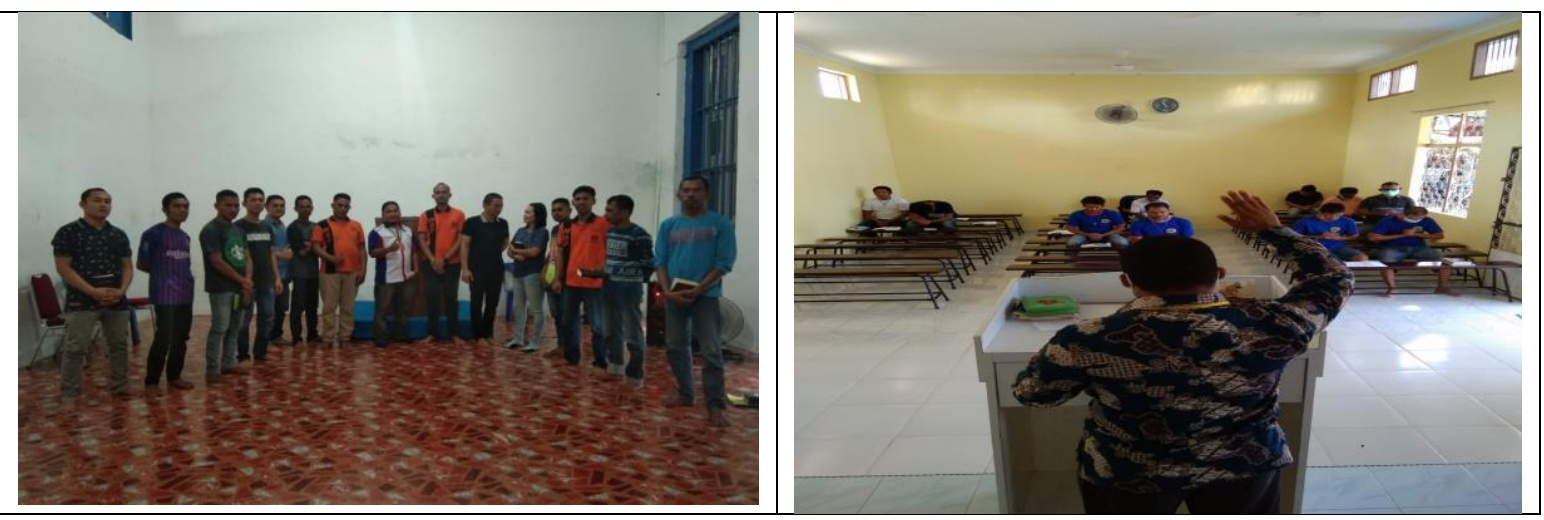

Gambar 1. Kegiatan Spritual Rutin Tim PkM di Lapas Umum Kelas II A Tanjungpinang

\section{HASIL DAN PEMBAHASAN}

Lapas sesuai fungsinya merupakan tempat melaksanakan pembinaan bagi para narapidana, tetapi justru kadang kala menjadi salah satu tempat yang sering terjadi kejahatan kekerasan yang dilakukan sesama narapida. ${ }^{2}$ Lembaga pemasyarakatan menjadi tempat yang berisiko tinggi terhadap perilaku kekerasan fisik, psikologis, dan ekonomi. ${ }^{3}$ Rasa frustasi yang dialami warga binaan akan meninbulkan ketegangan yang tumbuh dalam diri, antara dirinya dengan alam yang sempit, antara dirinya dan petugas dan aturan-aturan yang ada. ${ }^{4} \mathrm{Hal}$ itu dapat memberikan kepribadian dan karakter yang buruk bagi para warga binaan.

Warga Binaan perlu dibekali dengan pembinaan spiritual dan moral. Yang dapat memberikan warga Binaan pencerahan secara rohani. Sehingga ketika mereka kembali lagi di tengah masyarakat mereka dapat diterima dan berkarekter yang benar ditengah masyarakat. Oleh karena itu, mereka perlu dibekali dengan pemahaman Alkitab yang relevan untuk menghadapi tantangan masa depan.

\section{Spiritualitas Kristen}

Anamofa dalam David B. Perrin mengemukakan bahwa spritiualitas adalah pengalaman hidup manusia yang transendensi yang mengarahkan manusia kearah nilai tertinggi yang manusia itu terima. Dilanjutkan bagi Perrin kehidupan manusia adalah dunia yang memiliki niali-nilai. Secara khusus Perrin menjabarkan Spritualitas Kristen melibatkan seluruh aspek dari kehidupan manusia yang dasari oleh ketritunggalan Allah dalam Yesus Kristus dan Roh Kudus yang di ekspresikan dalam kehidupan

${ }^{2}$ Hevi Selvina, "Peran Lembaga Pemasyarakatan Dalam Penanggulangan Kekerasan Yang Dilakukan Oleh Narapidana," POENALE 5, No. 2 (2017): 1-10.2

3 Adiansyah And Sukihananto, "Kekerasan Fisik Dan Psikologis Pada Narapidana Lansia Di Lembaga Pemasyarakatan Jawa Barat,” Jurnal Keperawatan Indonesia 20, No. 3 (2017): 168-175.

${ }^{4}$ Ulang Mangun Sosiawan, "Upaya Penanggulangan Kerusuhandi Lembaga Pemasyarakatan," DE JURE 17, No. 3 (2017): 365-379.371 
sehari-hari. $^{5}$

Maka lingkungan, pola hidup dan ibadah dapat mempengaruhi pandangan individu terhadap kehiduannya. Karena tentunya hal itu akan membentuk spiritualitas. Jika kita menelaah pemikiran dari Perrin, tentunya kebiasaan atau lingkungan setiap individu itu menjadi faktor yang dapat mempengaruhinya dalam berperilaku. Oleh karena itu warga binaan harus diajarkan spiritualitas kristen. Karena spiritualitas kristen dibangun diatas dasar Firman Tuhan. Spiritualitas Kristen menekankan kasih didalamnya secara khusus kasih Allah akan manusia. L. Sihombing dalam tulisannya mengatakan seorang yang sudah mengalami kasih Allah secara konkret akan dimampukan mewujudkan kasih dalam konteksnya. Bila kita memperhatikan tulisan dalam Kitab Matius 22:37-40 jelas bahwa hukum yang pertama yang ditujukan kepada Allah sama hakekatnya dengan yang ditujukan kepada manusia. ${ }^{6}$ Demikian pula bila kita belajar pada pola hidup jemaat mula-mula jelas dalam Firman Tuhan kita dapat melihat pola hidup kasih dan keperdulian satu dengan yang lainnya diterapkan secara nyata.

Rick Waren dalam Edowai, menjalani hidup bersama-sama adalah bentuk dari persekutuan yang sesungguhya. Edowai melanjutkan bahwa orang yang hidup dalam ibadah dan persekutuan akan menumbuhkan kerohanian yang sehat dan sempurna. ${ }^{7}$ Bertumbuh secara spiritualitas yang baik mereka perlu diajarkan dan dibimbing hidup dalam pola ibadah yang benar, dengan demikikan akan

\section{Semangat dan Motivasi Spiritualitas Kristen bagi Warga Binaan}

Prihono menjabarkan bahwa motivasi sebagai sesuatu yang mengendalikan atau kekuatan yang dapat membawa individu mencapai kondisi terbaiknya. ${ }^{8}$ Sedangkan Supriyono dalam Pramesti mengatakan bahwa motivasi adalah kemampuan yang mengandung keinginan atau dorongan untuk berbuat sesuatu. ${ }^{9}$

Maka bila ingin warga binaan mengalami perubahan dalam hidupnya, akan dapat tercapai jika penggeraknya berubah. Spiritualitas Kristen mengajarkan ketundukan kepada Roh Kudus. Alkitab dalam kitab Kejadian 6:5 mengatakan bahwa manusia memiliki hati yang cenderung berbuat dosa. Bahkan dijelaskan dalam kitab Roma 8 bahwa keinginan daging bertentangan dengan keinginan Roh. Keinginan daging melakukan berbagai bentuk dosa. Tentunya keinginan daging yang dimaksud adalah kehendak dari manusia itu dimana daging adalah tubuh manusia.

Oleh karena itu manusia membutuhkan Roh Kudus yang menjadi kendali atas hidupnya. Memiliki ketundukan terhadap Roh Kudus artinya menyangkal segala keinginan daging sendiri. Begitu juga dengan warga binaan yang terdapat di dalam lapas. Motivasi spiritulitas kristen menjadi unsur penting bagi mereka sebagaimana itu penting juga bagi semua umat kristen.

\section{Penerapan Spiritualitas Kristen Kepada Warga Binaan.}

\footnotetext{
5 Jusuf Nikolas Anamofa, “Tinjauan Buku Studying Christian Spirituality,” UNIVIERA 2, No. 2 (2013): 144-151.145-146

${ }^{6}$ Lotnatigor Sihombing, "Spiritualitas Yang Utuh,” Amanat Agung 12, no. 2 (2016): 247-271.259

7 Dolince Edowai, "Pengaruh Ibadah Persekutuan Mahasiswa Papua ( IPMP ) Terhadap Pertumbuhan Rohani Mahasiswa Papua Di Kota Makassar,” Jaffray (2018): 185-196.187-188

${ }^{8}$ Prihono, I Ketut Budiartha, and Ida Bagus Putra Astika, "Pengaruh Motivasi, Budaya Organisasi Dan Spiritualitas Pada Kinerja Pegawai Kantor Pelayanan Perbendaharaan Negara Di Provinsi Bali," E-Jurnal Ekonomi dan Bisnis Universitas Udayana 5, no. 7 (2016): 2063-2090.2069

9 Maya Wulan Pramesti, "Motivasi : Pengertian, Proses Dan Arti Penting Dalam Organisasi," Gema Eksos 8, No. 2 (2013): 19-38.23
} 
Dari penjabaran diatas maka yang mejadi pertanyaan adalah bagaimana caranya menerapkan spiritualitas kristen kepada warga binaan. Tentunya salasatu cara yaitu dengan persekutuan. Persekutuan perlu diadakan di dalam lapas. Sebaimana kita ketahui bahwa para penghuni lapas adalah mereka yang tidak memiliki hak kebebasan oleh karena pelanggaran hukum yang mereka lakukan. Jika orang lain yang memiliki spiritualitas kristen yang baik atau pelayan Tuhan tidak datang kepada mereka di dalam lapas. Tentunya mereka tidak akan dapat datang kepada persekutuan yang akan membangun spiritualitas mereka.

Melalui persekutuan warga binaan akan memperoleh pengajaran. Dimana pengajaran dalam persekutuan yaitu didasari oleh Injil. Marthin Luther dalam Latif pengajaran agama bertujuan menyadarkan orang akan dosa serta bersukacita oleh firman yang memerdekakan melalui Yesus Kristus. Latif membandingkan pendapat Luther dengan John Calvin dalam pengartina pengajaran agama menurut padangan kedua tokoh besar gereja ini. menurut Calvin pengajaran membawa orangorang untuk mengabdi kepada Allah Bapa dan Yesus Kristus. ${ }^{10}$

Latif menjelaskan ditinjau dari kitab Efesus 4 dan Kisah Para Rasul 2 ada 8 hal yang Alkitab berikan berkaitan dengan kedewasaan rohani yang bertumbuh sesuai dengan kepenuhan Kristus yaitu: Mencapai kesatuan iman;Memiliki pengetahuan yang benar tentang Kristus; Teguh berpegang kepada kebenaran; Bertumbuh dalam kasih kepada Allah dan sesama; Meningkat hubungan dengan Allah; Terjadi kesatuan antar sesama anggota jemaat; Hidup yang memberkati sesama; Berani memikul tanggung jawab dalam pelayanan. ${ }^{11}$

Pratt dalam Sairwona mengatakan bahwa golongan kristen memeiliki keunikan yang khas yaitu kehidupannya yang dapat menyentuh banyak bidang. Berkaitan dangan persekutuan Sairwona memaknai pemberitaan Firman Tuhan sebagai terwujudnya hubungan-hubungan personal Allah dengan umat-Nya. Dapat kita melihatnya cerita dalam Yeremia 10:25, Yesaya 37:20 dan Hosea 4:1$2 .^{12}$

Oleh karena itu persekutuan perlu dilakukan kepada warga binaan di dalam lapas. Selain dari pada kepentingan rohani, terjadinya perubahan dari sikap yang buruk kearah perilaku masyarakat yang baik sebagai masyarakat secara hukum adalah salah satu hal yang ingin dicapai oleh pemerintahan tentunya. Dalam Kisah Para Rasul 2:42 dituliskan bahwa jemaat mula-mula mengalami pertumbuhan dalam kualitas dan kuantitas, dah peristiwa ini terjadi dalam ketekunan terhadap persekutuan yang merupakan kebiasaan jemaat mula-mula. hal ini ditanggapi oleh Warren dalam Latif, Warren mengatakan bahwa pertumbuhan merupakan akibat yang wajar dalam pelayanan. Pengajaran yang benar dan misi yang seimbang akan menghasilkan pertumbuhan secara kuantitas maupun kualitas. ${ }^{13}$

Perubahan yang diharapkan dialami oleh warga binaan tentunya, perubahan sikap atau perilaku dan pola pikirnya. Mereka yang tadinya memiliki kecenderungan untuk melakukan tindak kriminal atau pelanggaran menjadi individu yang berperilaku baik dan taat. Secara khusus tentunya mereka yang tadinya tidak takut akan Tuhan, tidak mengerti Firman menjadi mengerti dan hidup dalam takut akan Tuhan. Semua itu dapat disimpulkan harapan perubahan yang terjadi oleh warga binaan adalah kualitas hidup mereka.

${ }^{10}$ Helen Farida Latif, "Pengaruh Pengajaran Dan Persekutuan Terhadap Tingkat Pertumbuhan Rohani Anak Dan Remaja," EPIGRAPHE 1, No. 1 (2017): 119-138.121

${ }^{11}$ Ibid. 123

${ }^{12}$ Wellem Sairwona, "Kajian Teologis Penyampaian Firman Tuhan Dan Pengaruhnya Bagi Pertumbuhan Iman Jemaat," Shanan Jurnal Pendidikan Agama Kristen 1, no. 2 (2017): 116-131.118

${ }^{13}$ Latif, "Pengaruh Pengajaran Dan Persekutuan Terhadap Tingkat Pertumbuhan Rohani Anak Dan Remaja."123 


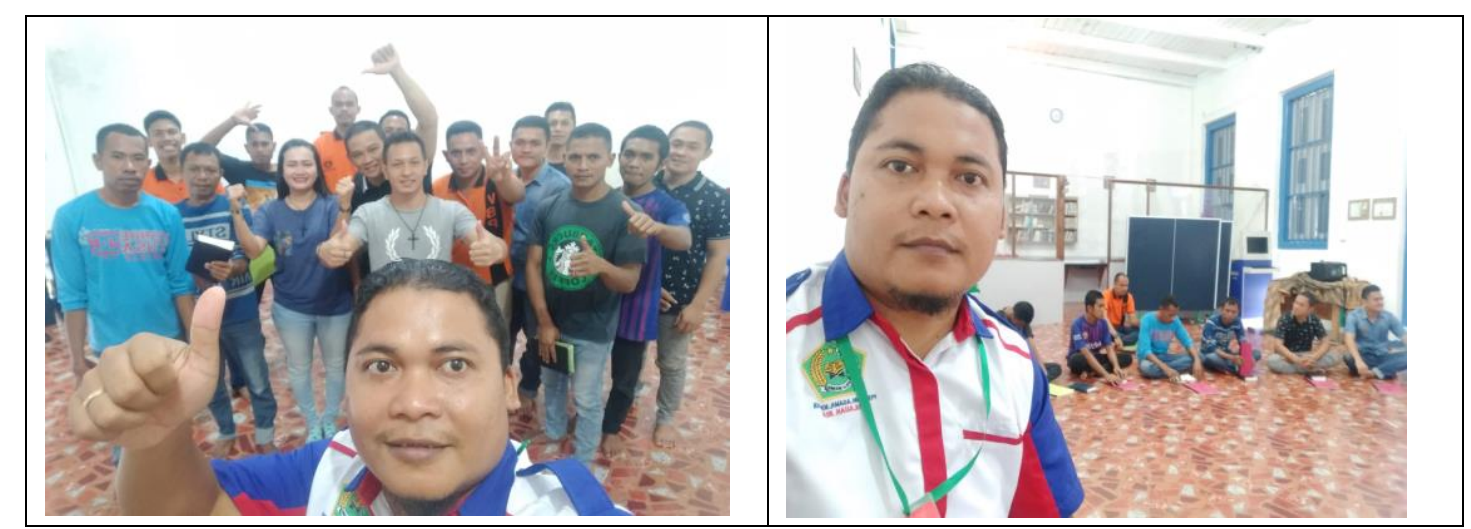

Gambar 2. Kegiatan Pembinaan Berkelompok di Lapas Umum Kelas II A Tanjungpinang

\section{SIMPULAN}

Warga binaan mengalami perubahan kearah yang baik bukan hanya kepentingan gereja ataupun lembaga pendidikan kristen saja melainkan tujuan yang ingin dicapai oleh negara juga. Tentunya baik buruknya perilaku warga binaan dalam lapas itu dipengaruhi oleh spiritualitas mereka. Warga binaan perlu dimotivasi agar dapat membangun sprititualitas mereka menjadi baik. Tentunya mereka memerluka orang-orang lain yang berasal dari luar kumpulan masyarakat lapas. Mereka perlu penerimaan, yaitu kerelaan kita datan kepada mereka dan mengadakan persekutuan kepada mereka. Melalui persekutuan warga binaan dapat memperoleh pengajaran agama yang didasari oleh Alkitab. Melalui itu mereka dapat mengenal Kristus dan meneladaninya dalam hidup. Melalui persekutuan warga bindaan dalam diajarkan tentang Firman yang memerdekakan. Dengan demikian spiritualitas kristen dalam diri warga binaan dapat bertumbuh. Mereka menjadi orang yang mengerti kebenaran

\section{DAFTAR PUSTAKA}

Adiansyah, and Sukihananto. "KEKERASAN FISIK DAN PSIKOLOGIS PADA NARAPIDANA LANSIA DI LEMBAGA PEMASYARAKATAN JAWA BARAT." Jurnal Keperawatan Indonesia 20, no. 3 (2017): 168-175.

Anamofa, Jusuf Nikolas. “Tinjauan Buku Studying Christian Spirituality.” UNIVIERA 2, no. 2 (2013): $144-151$.

Edowai, Dolince. "Pengaruh Ibadah Persekutuan Mahasiswa Papua ( IPMP ) Terhadap Pertumbuhan Rohani Mahasiswa Papua Di Kota Makassar." Jaffray (2018): 185-196.

Latif, Helen Farida. "Pengaruh Pengajaran Dan Persekutuan Terhadap Tingkat Pertumbuhan Rohani Anak Dan Remaja." EPIGRAPHE 1, no. 1 (2017): 119-138.

Pramesti, Maya Wulan. "Motivasi : Pengertian, Proses Dan Arti Penting Dalam Organisasi." Gema Eksos 8, no. 2 (2013): 19-38.

Prihono, I Ketut Budiartha, and Ida Bagus Putra Astika. "PENGARUH MOTIVASI, BUDAYA ORGANISASI DAN SPIRITUALITAS PADA KINERJA PEGAWAI KANTOR PELAYANAN PERBENDAHARAAN NEGARA DI PROVINSI BALI.” E-Jurnal Ekonomi dan Bisnis Universitas Udayana 5, no. 7 (2016): 2063-2090.

Sairwona, Wellem. "KAJIAN TEOLOGIS PENYAMPAIAN FIRMAN TUHAN DAN PENGARUHNYA BAGI PERTUMBUHAN IMAN JEMAAT." Shanan Jurnal Pendidikan Agama Kristen 1, no. 2 (2017): 116-131.

Selvina, Hevi. "Peran Lembaga Pemasyarakatan Dalam Penanggulangan Kekerasan Yang Dilakukan Oleh Narapidana." POENALE 5, no. 2 (2017): 1-10.

Sihombing, Lotnatigor. "Spiritualitas Yang Utuh.” Amanat Agung 12, no. 2 (2016): 247-271.

Sosiawan, Ulang Mangun. "UPAYA PENANGGULANGAN KERUSUHANDI LEMBAGA PEMASYARAKATAN.” DE JURE 17, no. 3 (2017): 365-379. 